Florida State University College of Law

Scholarship Repository

Scholarly Publications

2014

\title{
A Behavioral Justification for Escalating Punishment Schemes
}

Murat C. Mungan

Florida State University College of Law

Follow this and additional works at: https://ir.law.fsu.edu/articles

Part of the Criminal Law Commons, and the Law and Economics Commons

\section{Recommended Citation}

Murat C. Mungan, A Behavioral Justification for Escalating Punishment Schemes, 3737 INT'L REV. L. \& ECON. 9 (2014) 9 (2014),

Available at: https://ir.law.fsu.edu/articles/115

This Article is brought to you for free and open access by Scholarship Repository. It has been accepted for inclusion in Scholarly Publications by an authorized administrator of Scholarship Repository. For more information, please contact efarrell@law.fsu.edu. 


\title{
A Behavioral Justification for Escalating Punishment Schemes*
}

\author{
Murat C. Mungan ${ }^{\dagger}$
}

June 8, 2015

\begin{abstract}
The standard two-period law enforcement model is considered in a setting where individuals usually, but not exclusively, commit crimes only after comparing expected costs and benefits. Where escalating punishment schemes are present, there is an inherent value in keeping a clean criminal record; a person with a record may unintentionally become a repeat offender if he fails to exert self-control, and be punished more severely. If the punishment for repeat offenders is sufficiently high, one may rationally forgo the opportunity of committing a profitable crime today to avoid being sanctioned as a repeat offender in the future. Therefore, partial deterrence can be achieved at a very low cost through the use of escalating penalties, providing a behavioral justification for punishing repeat offenders more severely.
\end{abstract}

Keywords: Lapse, weak-will, recidivism, repeat offenders, law enforcement, deterrence, escalating penalties.

JEL Classification: D03, K00, K10, K14, K40, K42.

*I thank Tim Friehe, Nuno Garoupa, David Landau, Sam Wiseman, and the participants of the 2012 Florida State University College of Law Junior Faculty Workshop for useful comments and suggestions, and Kristan Rivers for valuable research assistance.

${ }^{\dagger}$ Assistant Professor of Law, Florida State University, College of Law, 425 W. Jefferson Street, Tallahassee, FL 32306-1601. e-mail: mmungan@law.fsu.edu; phone: 850.644. 2579; fax: 850.644 .5487 . 


\section{Introduction}

The scheme of punishing repeat offenders more severely than first time offenders is still puzzling from a law and economics perspective. ${ }^{1}$ Although the law and economics literature on escalating punishment schemes is broad and "escalating"2 not many articles appear to provide satisfying economic rationales for repeat offender laws. ${ }^{3}$ As one scholar very recently pointed out "[a]s intuitively appealing as [escalating] schemes appear, however, it has proven surprisingly difficult to show that they are consistent with an optimal (cost-minimizing) enforcement policy" Miceli (2012 p. 1).

The main objective of this article is to demonstrate that the strict assumptions in most economic analyses concerning the nature of offenders may be responsible for their inability to provide satisfying justifications for repeat offender laws. Despite many empirical studies, anecdotal evidence, and legal commentary providing support for the contrary ${ }^{4}$ mainstream economic analyses continue to assume that offenders decide rationally, and that they always consciously maximize expected net-benefits. ${ }^{5}$ Meaningful departures from this assumption, especially in the context of criminal law -and even more specifically in analyzing repeat offender laws- are likely to increase the explanatory power of law and economics. ${ }^{6}$

More than forty years ago, Stigler noted that "[t]he first-time offender may have committed the offense almost accidentally and (given any punishment) with negligible probability of repetition, so heavy punishments (which have substantial costs to the state) are unnecessary" (Stigler (1970 pp. 528-529)).

\footnotetext{
${ }^{1}$ See, e.g., Emons (2007 p. 171) stating that "[f]or the well developed law and economics literature on deterrence escalating sanction schemes are still puzzling", and Utset (2007 p. 664), sub-section IV. E. The Puzzle of Higher Sanctions for Repeat Offenders. See also Polinsky and Shavell (1998) reviewing the previous law and economics literature, as well as criminal law scholarship, and concluding that "[t]he question of whether sanctions should depend on prior convictions has not been adequately addressed in the standard economic model of deterrence" Polinsky and Shavell (1998 p. 306).

${ }^{2}$ This refers to the title of Miceli (2012): Escalating Interest in Escalating Penalties.

${ }^{3}$ See Miceli (2012) providing a survey of the existing law enforcement literature on escalating punishment schemes, and concluding that "[e]conomic theory has had a hard time rationalizing this practice" Miceli (2012 at abstract). One explanation might be that economic analyses are incapable of providing such rationales, because recidivism laws reflect the maximization of non-economic or non-consequentialist values. The objective of this article is not to investigate whether this is true, but to demonstrate that economic analyses may be capable of providing stronger rationales once they incorporate behavioral assumptions.

${ }^{4}$ See, e.g., Jolls, Sunstein, and Thaler (1998), Robinson and Darley (2004) and McAdams and Ulen (2009) reviewing existing empirical studies. Korobkin and Ulen (2000) is an example of legal commentary arguing for the removal of the rational choice assumption from law and economics.

${ }^{5}$ An exception is Emons (2007) which is briefly reviewed later in this section.

${ }^{6}$ McAdams (2012) also highlights the importance of departures from standard assumptions (e.g. through the incorporation of "weakness of will, impulsiveness, myopia, or bounded willpower" (McAdams (2012 p. 1607)) in studying criminal law ). Unlike the instant article, McAdams (2012) is mainly concerned with implications concerning general deterrence and addiction. Similarly, Mungan (2012) argues that if economic analyses incorporate behavioral assumptions they can provide satisfying rationales for a variety of prevalent practices in criminal law including punishing repeat offenders more severely. However, that article, unlike the instant one, relies on the information revealing function of criminal law rules and procedures.
} 
Later, in 1991, Cooter observed that "[p]eople often commit torts or crimes due to weakness of will" (Cooter (1991) p. 149) and attempted to incorporate "weakness of will" into the standard economic theory. Since then, many scholars have pointed out and documented that some offenses are committed impulsively rather than as a result of conscious decision making guided by a cost-benefit analysis. ${ }^{7}$ Despite these developments, there have not been many attempts to incorporate decision-makers who lack full self-control into the law enforcement literature analyzing repeat offender laws. ${ }^{8}$ This is the purpose of this article: to demonstrate how the simplest law enforcement model becomes capable of providing an economic rationale for escalating penalty schemes when weak-willed potential offenders are considered.

By weak-willed, I mean potential offenders who ordinarily possess self-control, but who may lapse into committing crime. ${ }^{9}$ An individual who possesses selfcontrol decides whether or not to commit crime based on a cost-benefit analysis, whereas a person who acts impulsively fails to consider the consequences of his actions. Perhaps paradoxically, this approach allows the formalization of what might be perceived as over-compliance in standard law enforcement models; individuals may forgo the opportunity of committing seemingly profitable crimes. In other words, a person may choose to comply with a law, even if breaking that law would lead to a sanction that costs less than the criminal benefits to the potential offender. Though this may seem puzzling, many of us engage in this type of behavior frequently.

One may not report a minor car accident to his insurance company, even if he knows his insurance rate will not go up with the reporting of a single accident. Similarly, a person may prefer not to speed, even if by doing so she would obtain benefits greater than the cost of the speeding ticket. Both examples provide hints as to why the weak-willed potential offender may prefer to comply with the law even if the criminal benefit is higher than the sanction for first time offenders. The person's decision is guided by future considerations in both examples. The insured does not report the minor accident, because he wants to have the ability to report more expensive accidents in the future without having increases in his policy rate. The driver may abstain from speeding, because she wants to be able to accumulate points on her drivers' license in future and more important occasions that will require her to speed. Just like these two individuals, the weak-willed potential offender has a reason to do something that is not in his short-term best interest. He complies with the law today, so that he preserves a clean record when he lapses in the future and commits a crime. This way he avoids the penalty for repeat offenders, which is ordinarily greater than the penalty for first time offenders. I call this over-complicance generating effect of escalating penalties the temporal spillover effect.

\footnotetext{
${ }^{7}$ See, e.g. Robinson and Darley (2004) and the references cited therein. See also McAdams (2012) reviewing the existing economics literature studying willpower in the context of criminal law.

${ }^{8}$ For exceptions, see Utset (2007) and Baumann and Friehe (2012), which are briefly discussed below.

${ }^{9}$ Section 3.1. discusses how this assumption relates to the literature on present-bias.
} 
If punishment is costly, as is clearly the case when imprisonment is used, then one can take advantage of potential offenders' anticipatory behavior. A high sanction for repeat offenders deters individuals who currently possess selfcontrol, even if the punishment for a first time offender is very low. By setting the punishment for first time offenders very low, and the sanction for repeat offenders sufficiently high, one can simultaneously deter individuals with a clean record and minimize the cost of punishing individuals who lapse and commit crime. The possibility of achieving a degree of deterrence while reducing punishment costs makes escalating penalties socially desirable. This justification for escalating punishments relies on the assumption that individuals lack full self-control, and rarely lapse into committing crime; but for this assumption, individuals would not have a reason to forgo profitable criminal opportunities, because once they build up a criminal record, they can simply stop committing crimes.

This rationale does not rely on specific assumptions concerning the efficiency of offenses. Justifications for escalating penalty schemes exist when crimes are inefficient, but also when some are efficient. Similarly, optimal escalating penalties are present when criminal benefits enter the social calculus as well as when they do not. Moreover, it is not necessary to assume that punishment costs more when committed by individuals who lapse. These assumptions are in some regards weaker than those used in other articles analyzing the economics of repeat offender laws that incorporate individuals who are punished without (breaking or) intending to break the law. Examples include Emons (2007), Chu et al. (2000), and Mungan (Forthcoming). Emons (2007) incorporates individuals who may accidentally commit crimes, and concludes that if criminal benefits are in a certain parametric range, then escalating punishments are optimal. That article, unlike the instant one, relies on criminals having historyindependent strategies (i.e. they either always or never intentionally commit crime), punishment being costless, and the existence of a constraint on the total sanctions that can be imposed on criminals. Chu et al. (2000) consider an imperfect legal system which convicts innocent individuals with a certain probability, whereas Mungan (Forthcoming) focuses on the possibility of individuals being uninformed of the illegality of various acts. The last two articles assume that there are social costs associated with the punishment of innocent and uninformed individuals, respectively, and conclude that the punishment of repeat offenders can be justified on grounds that they reduce such costs.

I am not claiming that the economic rationale identified in this article is the only -or most important- one that provides a justification for escalating punishment schemes. My primary objective is to demonstrate that simple behavioral assumptions can provide strong economic justifications for repeat offender laws, even under the simplest sets of assumptions. Accordingly, the instant article is complementary to the existing literature, which generally does not rely on behavioral assumptions, and contains at least three broad sub-categories. ${ }^{10}$ One

\footnotetext{
${ }^{10}$ See Miceli (2012) for another review of the existing literature on escalating punishment schemes.
} 
line of research asserts that the stigmatization effect of the first criminal penalty may give it greater force than subsequent penalties, which may make escalating punishment schemes optimal (e.g. Funk (2004), Rasmusen (1996) and Miceli and Bucci (2005)). Another strand of literature points out that individuals may have different tendencies to commit crime. In this framework, escalating penalties can be used to distinguish between high-tendency and low-tendency criminals (e.g. McCannon (2009), Miceli (2012), Mungan (2012), Polinsky and Rubinfeld (1991) and Utset (2007)). Finally, there are articles suggesting that offenders may learn how to avoid detection and/or relevant characteristics of the criminal system (e.g. Friehe (2009) and Mungan (2010)). This could increase the tendency of repeat offenders to commit crimes, justifying more severe punishment. The observations made in these three strands of literature should be equally valid when people occasionally lack self-control, and therefore the instant article complements this literature.

This article also complements the emerging theoretical literature incorporating behavioral assumptions into the analysis of optimal punishments for repeat offenders. Emons (2007), briefly discussed above, assumes that criminals occasionally commit crime by accident. That assumption is functionally very similar to the 'lapsing assumption' incorporated in this article. But, because Emons (2007) assumes that punishment is costless and because criminals must choose from history-independent strategies, it is unable to capture the temporal spillover effect identified in this article. Baumann and Friehe (2012) considers individuals who suffer from present-bias, who are, at least to some degree, aware of their self-control problems. These individuals resemble, to some extent, those that are considered in this article. A present-biased criminal, like an individual who experiences a lapse, may commit a non-profitable ${ }^{11}$ crime "when the criminal benefit is immediate and the expected sanction is heavily discounted due to the individual's present bias." ${ }^{12}$ Bauman and Friehe (2012) asks a positive and different question than the normative one posed in this article: can selfreporting be used as a commitment device by present-biased individuals when escalating penalties are present? Thus, whereas Baumann and Friehe (2012) take escalating penalty schemes as given and investigate the potential implications of such schemes, the instant article demonstrates that a temporal spillover effect emerges and shows that this effect provides a partial justification for repeat offender laws. Utset (2007) also considers present-biased offenders, and comments on how escalating penalties can be used to separate between "offenders with different levels of present-bias." ${ }^{13}$ Unlike the instant article, it does not consider costly sanctions or the possibility of offenders potentially having fluctuating degrees of self-control, and therefore does not capture the temporal spillover effect identified in this article.

To formalize the temporal spillover effect of punishing repeat offenders more severely, and to demonstrate how this effect might make escalating penalties

\footnotetext{
${ }^{11}$ To be specific a non-profitable crime is one for which the present discounted value of the expected sanction off-sets the benefit from crime.

${ }^{12}$ Baumann and Friehe (2012) at 728.

${ }^{13}$ Utset (2007 at 664).
} 
optimal, I use a standard two-period model of law enforcement. This model is described in the next section where I derive optimality conditions for escalating punishment schemes. Section 3 discusses how the assumption that some individuals rarely lapse and commit crime relates to the literature on present-bias, discusses how results are affected by the incorporation of various alternative assumptions, summarizes my findings, and presents a few concluding remarks.

\section{A Simple Model and Optimality Analysis}

An act causes harm of $h$ to society and confers a private benefit of $b$ to the person committing it. There are two periods in which individuals can commit the illegalized act. The act is inefficient $(b<h){ }^{14}$ Therefore, to deter the commission of this act, the government declares it a crime and announces $s_{1}$ and $s_{2}$, which are respectively the sanctions for first time and repeat offenders. Sanctions are socially costly to impose. Following Polinsky and Shavell (2007), I assume that imposing a sanction of $s$ results in social costs of $\theta s .{ }^{15}$ To simplify the analysis, it is assumed that the government possesses a perfect detection mechanism, which catches all individuals committing crime.

Individuals ordinarily (with a probability of $(1-q)$ ) decide whether or not to commit a crime based on a cost-benefit analysis and seek to maximize expected values without discounting future values. But, they lack full self-control, and in each period they may 'lapse' (with a probability of $q \in(0,1)$ ), in which case they do not compare costs and benefits, and commit crime. Whether or not an individual lapses is (randomly) determined at the beginning of each period. The probability of a lapse $(q)$ is constant across periods, therefore, the probability with which an individual experiences a lapse in the second period does not depend on whether he lapsed in the first period. Based on these assumptions, the decision tree an individual faces at the beginning of period 1 can be represented by figure 1 , below.

\section{[Insert Figure 1]}

The government cannot determine whether an individual committed crime based on a cost-benefit analysis or because he lapsed. But it knows the relevant parameters (i.e. $h, b, q$, and $\theta$ ), and its objective is to maximize social welfare or, equivalently, minimize net social costs. There are two components of net social cost: aggregate punishment costs and the cost of crime net of criminal benefits. ${ }^{16}$ The government may impose uniform, declining or escalating sanc-

\footnotetext{
${ }^{14}$ This assumption is not necessary and only simplifying. In section 3 , I demonstrate that results are preserved when there are some people with benefits greater than $h$ in addition to people with $b<h$. I also discuss the case where $b$ is distributed over $[0, \infty)$.

${ }^{15}$ See Polinsky and Shavell (2007 p. 410). This appears to be the most common way of incorporating costly sanctions.

${ }^{16} \mathrm{I}$ am including criminal benefits in the social welfare calculus, because this appears to be the most common approach. But, Stigler's question ("what evidence is there that society sets a positive value upon the utility derived from a murder, rape, or arson?" Stigler (1970 p. 527)) still has not been convincingly answered in the literature. Therefore, I consider the effects of excluding criminal benefits in section 3 , and conclude that qualitative results do not depend on this assumption.
} 
tion schemes. The analysis proceeds by identifying potentially cost minimizing sanction schemes of each type.

\subsection{Uniform Sanction Schemes $\left(s_{1}=s_{2}=s\right)$}

Any sanction scheme with $s \geq b$ deters all individuals ${ }^{17}$ who posses selfcontrol, and in both periods. This implies that any uniform sanction scheme with $s>b$ is dominated by the sanction scheme $s=b$, because the latter scheme results in the same level of deterrence, but lower punishment costs (i.e. $\theta b$ per offense committed by those who lapse). A similar argument reveals that penalty schemes of the form $b>s>0$ are dominated by the sanction scheme $s=0$; both schemes fail to deter any individual who possesses self-control, but the latter scheme results in lower punishment costs. This brief analysis reveals the following result:

Observation 1: Uniform sanctions such that $s \notin\{0, b\}$ cannot be optimal.

In the proceeding parts, the two remaining sanction schemes will be called $U_{b}$ and $U_{0}$ where subscripts refer to the size of the uniform sanction.

\subsection{Escalating Sanction Schemes $\left(s_{1}<s_{2}\right)$}

Any escalating sanction scheme with $s_{1} \geq b$ deters all individuals who are able to exert self-control. But, the uniform sanction scheme $U_{b}$ achieves the same result, and at a lower punishment cost, because it imposes lower sanctions to all individuals who commit crime upon losing self-control. As such, escalating sanction schemes where $s_{1} \geq b$ are inefficient. Similarly, escalating penalties of the form $b>s_{2}>s_{1}$ are sub-optimal, because they fail to deter all individuals who possess self-control, and result in higher punishment costs than scheme $U_{0}$.

The remaining escalating sanction schemes are of the form $s_{2} \geq b>s_{1}$. When faced with a sanction scheme of this form, individuals who do not lose self-control in the first period know that with a probability of $q$ they will lack self-control in the second period and commit crime. As such, they know that committing crime in the first period will lead them to become repeat offenders in the second period with a probability of $q$ and results in an expected loss of $q\left(s_{2}-b\right)$ in the second period. Hence, the expected pay-off from committing crime in the first period is:

$$
b-s_{1}+q\left(b-s_{2}\right)
$$

Not committing crime, on the other hand, results in a pay-off of 0 in the first period, and a benefit of $\left(b-s_{1}\right)$ in the second period. This follows because the potential offender enters the second period with a clean record, which guarantees a sanction of $s_{1}$ if he commits crime. Therefore, he intentionally commits crime in the second period if he does not lose control, and unwittingly commits crime in the second period if he does lose self-control. As such, he is willing to commit crime in the first period iff:

$$
b-s_{1}+q\left(b-s_{2}\right)>b-s_{1}
$$

\footnotetext{
${ }^{17}$ Indifferent individuals are assumed to not commit crime.
} 
This condition never holds since $s_{2} \geq b$. Hence, escalating sanction schemes of the form $s_{2} \geq b>s_{1}$ induce individuals who possess self-control to refrain from committing crime in the first period, but to commit crime (intentionally or unwittingly) in the second period. This formalizes what I have termed the temporal spillover effect of escalating penalties in the introduction. Among these sanction schemes only $s_{1}=0, s_{2}=b$, which will be called $E$ in the proceeding parts of this article, can potentially be optimal because the remaining sanction schemes result in the same level of deterrence as $E$, but produce greater punishment costs. This brief analysis is summarized by observation 2 , below.

Observation 2: All escalating sanction schemes such that $s_{1} \neq 0$ or $s_{2} \neq b$ are inefficient.

\subsection{Declining Sanction Schemes $\left(s_{1}>s_{2}\right)$}

Declining sanction schemes of the form $s_{1}>s_{2} \geq b$ and $b>s_{1}>s_{2}$ cannot be optimal, because they produce unnecessary punishment costs as explained in the context of escalating and uniform punishment schemes. The remaining declining sanction schemes are of the form

$$
s_{1} \geq b>s_{2}
$$

Under this scheme, any person who enters the second period as a repeat offender prefers to commit a crime. As such, by committing a crime in the first period, a person's aggregate expected pay-off is:

$$
2 b-s_{1}-s_{2}
$$

To identify a person's expected pay-off from not committing a crime in the first period, note that a person with a clean record in the second period is unwilling to commit a crime, because this results in a sanction of $s_{1}>b$. Therefore, a person who abstains from committing a crime in the first period knows that he will commit a crime in the second period only if he loses self-control which happens with a probability of $q$. Hence, the expected pay-off from not committing a crime in the first period is $q\left(b-s_{1}\right)$. Therefore, a person commits a crime in the first period iff:

$$
(2-q) b>(1-q) s_{1}+s_{2}
$$

Declining sanction schemes satisfying this condition cannot be optimal either, because these sanction schemes do not deter any self-control possessing individual, and lead to greater punishment costs compared to the scheme $U_{0}$. As such, only those schemes that satisfy (6) below can potentially be optimal.

$$
(2-q) b \leq(1-q) s_{1}+s_{2}
$$

Next, note that if the inequality in (6) holds strictly, punishment costs can be reduced without affecting deterrence by lowering either $s_{1}$ or $s_{2}$ until the left and right hand sides of (6) are equal. Therefore, all declining schemes besides those of the form

$$
(2-q) b=(1-q) s_{1}+s_{2}
$$


are inefficient. Finally, note that given any sanction scheme that satisfies (7), one can reduce $s_{1}$ by one unit and increase $s_{2}$ by $(1-q)$ units and still satisfy (7). Such moves reduce the amount by which first time offenders are punished by more than the amount by which the punishment of repeat offenders is increased. Since, by definition, the number of first time offenders is no less than the number of repeat offenders, such moves reduce total punishment costs and therefore enhance welfare. As such, to find the best declining sanction scheme, $s_{1}$ should be decreased and $s_{2}$ should be increased as much as conditions (7) and (3) permit. Strictly speaking, one cannot identify the best declining sanction scheme, because it requires $s_{2}$ to be smaller than but infinitesimally close to $b$, and $s_{1}$ to be greater than but infinitesimally close to $b$. But, for our purposes (of comparing the maximum achievable welfare under declining sanction schemes to welfare achievable under other schemes) it is harmless to assume that the best declining sanction scheme is $s_{1}=b+\varepsilon$ and $s_{2}=b-(1-q) \varepsilon$, where $\varepsilon$ is a number very close to zero. This sanction scheme will be called $D$ in the remaining parts of this article. This analysis is summarized by the following observation.

Observation 3: Let $C_{D}$ denote net social costs generated by scheme D. All declining sanction schemes result in greater net social costs than $\lim _{\varepsilon \rightarrow 0} C_{D}(\varepsilon)$.

\subsection{Optimality Analysis}

There are only four sanction schemes which remain as candidates for the optimal sanction scheme: $U_{b}, U_{0}, E$, and $D$. This section contains a few propositions which together determine the optimal sanction scheme by comparing social welfare under all four.

Proposition 1: Declining sanction schemes cannot be optimal. In particular, $U_{b}$ dominates $D$.

Proof: Under D, no individual intentionally commits crime in the first period, as such the number of individuals who commit crime in the first period is $q$. In the second period, among the $(1-q)$ individuals who possess clean records, $q$ proportion lapse and commit crime. The rest of the individuals who have a clean record, do not commit crime because $s_{1}>b$. q individuals who have a criminal history (because they lapsed in the first period) commit (intentionally or due to a lapse) crime in the second period because $b>s_{2}$. As such, a total of $3 q-q^{2}$ crimes are committed, and social costs are given by:

$C_{D}=\left(3 q-q^{2}\right)(h-b)+q \theta(b-(1-q) \varepsilon)+\left(2 q-q^{2}\right) \theta(b+\varepsilon)>\left(3 q-q^{2}\right)(h+\theta b-b)$

Under $U_{b}$, only those individuals who lose self-control commit crime. As such, a total of $2 q$ individuals commit crime, and all individuals are subjected to sanctions of $b$. As such, social costs are given by:

$$
C_{U_{b}}=2 q(h+\theta b-b)
$$

It is clear that $C_{D}>C_{U_{b}}$ ( since $\left.C_{D}-C_{U_{b}}=q(1-q)(h+\theta b-b)>0\right)$.

The main rationale behind the inefficiency of declining sanction schemes relates to incentives provided to ex-criminals. Declining sanction schemes provide 
a discount in sanctions to individuals who have a prior record, and one great enough to incentivize them to commit crime. Therefore, individuals who lapse into committing crime in the first period commit crime again in the future, and this results in social costs.

Next, the relationship between escalating punishment schemes and severe uniform punishment schemes is investigated.

Proposition 2: E results in greater welfare than $U_{b}$ when $\frac{\theta b}{h-b}>\frac{1}{q(2-q)}-1$, i.e. when per person punishment costs are large and when gains from deterrence is small.

Proof: It follows from (2) and the proceeding discussion that under E; individuals commit crime in the first period only if they lapse, individuals with a clean record commit crime in the second period (since $b>s_{1}$ ), and individuals with an offense history refrain from committing crime unless they lapse. Hence, $q$ individuals commit crime in the first period, because they lapse. $(1-q) q$ of these individuals refrain from becoming repeat offenders because they possess selfcontrol, and $q^{2}$ of these individuals become repeat offenders, because they lapse again. $(1-q)$ individuals refrain from committing crime in the first period, and commit crime (intentionally or unwittingly) in the second period. Therefore, the total number of offenses is given by $\left(1+q^{2}\right)$, and $q^{2}$ of these constitute repeat offenses. Therefore, total cost is given by:

$$
C_{E}=\left(1+q^{2}\right)(h-b)+q^{2} \theta b
$$

This is smaller than $C_{U_{b}}$ as specified in (P.2.) iff

$$
2 q(h+\theta b-b)>\left(1+q^{2}\right)(h-b)+q^{2} \theta b
$$

Collecting $(h-b)$ 's and $\theta b$ 's on separate sides (P.4.) becomes:

$$
q(2-q) \theta b>(1-q(2-q))(h-b)
$$

Finally, by re-arranging we get:

$$
\frac{\theta b}{h-b}>\frac{1}{q(2-q)}-1
$$

The economic intuition behind proposition 2 lies in the incentives provided through escalating punishment schemes. By imposing large sanctions on repeat offenders, escalating penalties give individuals a reason to avoid obtaining a criminal record. Individuals know that they are not perfect in terms of exercising self-control. Therefore, they want to avoid the possibility of unintentionally becoming a repeat offender in the second period and being subject to greater sanctions. This requires skipping profitable criminal opportunities in the first period, and delaying the commission of crime to the second period. This temporal spillover effect allows setting the penalty for first time offenders at very low levels, since it is the prospect of unintentionally becoming a repeat offender that deters an individual and not the sanction for committing his first offense. As such, escalating penalties result in some level of under-deterrence but very 
low aggregate punishment costs. Since the reverse is true for severe uniform sanction schemes, the higher punishment costs (i.e. $\theta b)$ and the lower the cost of under-deterrence (i.e. $h-b$ ), the more likely escalating punishments are optimal.

The analysis proceeds by identifying the conditions under which lenient uniform punishment schemes $\left(i . e . U_{0}\right.$ ) are dominated by escalating punishment schemes, although one may reasonably be tempted to rule them out as being uninteresting,

Proposition 3: $E$ results in more welfare than $U_{0}$ when $\frac{1}{q^{2}}-1>\frac{\theta b}{(h-b)}$, i.e. when the per person punishment cost is small and when gains from deterrence is large.

Proof: Under $U_{0}$, no-one is deterred, because $b>s_{1}=0$. Therefore, the measure of offenses is 2. Since no one is punished, there are no punishment costs. Hence, total costs are given by:

$$
C_{U_{0}}=2(h-b)
$$

This is greater than $C_{E}$ as specified in (P.3.) if:

$$
2(h-b)>\left(1+q^{2}\right)(h-b)+q^{2} \theta b
$$

Re-arranging we have:

$$
\frac{1}{q^{2}}-1>\frac{\theta b}{h-b}
$$

Proposition 3 formalizes the simple trade-off between partial deterrence and punishment costs. The escalating punishment scheme $E$ deters all individuals who do not lapse in the first period, and individuals with a prior record in the second period. Compared to $U_{0}$, which does not lead to such partial deterrence, $E$ only costs $q^{2} \theta b$, which is incurred due to the punishment of a small number (i.e. $q^{2}$ ) of repeat offenders. Therefore, if $q$ is sufficiently small $U_{0}$ is inefficient.

Corollary 1: Escalating punishment schemes are optimal when

$$
g(q)=\frac{1}{2 q-q^{2}}-1<\frac{\theta b}{h-b}<\frac{1}{q^{2}}-1=f(q)
$$

and there exist $\theta, b$ and $h$ that make escalating penalties optimal.

The first portion of corollary 1 summarizes the findings of Propositions 1, 2 and 3 , and the second portion follows immediately when one compares $f(q)$ and $g(q)$ as specified in (8). More specifically, $f(q)>g(q)$ whenever $q$ is interior. Figure 2, below, plots $f(q)$ and $g(q)$ to allow a visualization of the conditions under which escalating punishments are optimal. This figure suggests that when punishment costs $(\theta b)$ and gains from deterrence $(h-b)$ are balanced or are not extreme in relation to each other, escalating penalties are optimal. Furthermore, as long as $q$ is small, $E$ is very likely to dominate $U_{0}$. If this is true, and zero deterrence is not optimal, there is a large enough $\theta$ that makes escalating penalties socially desirable.

\section{[Insert Figure 2]}


The rationale behind this result is partially explained by the discussions proceeding propositions 2 and 3, and can briefly be stated as follows. The advantage of escalating punishment schemes is to give individuals an incentive to delay committing crime until the second period without using costly punishment methods for first time offenders. Under escalating punishment schemes, individuals have this incentive because they fear that they may be subjected to large sanctions for repeat offenders in the second period if they intentionally commit crime in the first period and lapse in to committing crime in the second period. By incentivizing individuals to delay committing crime, escalating penalties achieve partial deterrence. Furthermore, punishment costs are relatively small, because only repeat offenders are punished severely, and only individuals who lapse twice become repeat offenders. Since the probability of this happening is relatively small (i.e. $q^{2}$ ), aggregate punishment costs are relatively small.

The disadvantage of escalating punishments, in comparison to very lenient uniform punishment schemes, is that they result in increased punishment costs. But, as long as the probability of a lapse is small, the gains from the deterrence of an additional $\left(1-q^{2}\right)$ crimes should off-set the cost of punishing $q^{2}$ individuals. The disadvantage of escalating penalties in comparison to severe uniform punishment schemes is the under-deterrence of an additional $(1-q(2-q))$ individuals. This represents a sizeable cost, especially if the harm from crime is high, and the benefit to offenders is small. Therefore, escalating penalties are optimal when there are significant punishment costs, which is precisely the assumption that was invoked by Stigler in his comment regarding escalating penalty schemes. ${ }^{18}$

\section{Remarks and Conclusion}

Next, I discuss the robustness of my model by considering the effects of relaxing various assumptions, and conclude.

\subsection{Partially Naive and Present-Biased Individuals}

To make the analysis as simple as possible, in section 2, I captured probabilistacly occuring self-control problems by assuming that people rarely lapse into committing crime. ${ }^{19}$ Self-control problems have recently received much attention in the law and economics literature. ${ }^{20}$ A particular self-control problem occurs when the person suffers from present-bias, ${ }^{21}$ which refers to a person's inability to forgo instant benefits even when this implies a larger than justified future cost. If $U_{t}$ represents the offender's utility function, $\beta$, a parameter discounting future events over events in the present, can be used to represent

\footnotetext{
18 "... punishments (which have substantial costs to the state) ..." Stigler (1970 p. 529).

${ }^{19}$ For a similar assumption used in the literature see Emons (2007).

${ }^{20}$ See Fennell (2009) for a review of previously identified self-control problems, and their relevance to legal policy.

${ }^{21}$ See McAdams (2011) discussing present bias in the context of criminal law.
} 
present-bias problems: ${ }^{22}$

$$
U_{t}=u_{t}+\beta\left(u_{t+1}+u_{t+2}+u_{t+3}\right)
$$

where $u_{t}$ denotes the expected utility at time $t$. In this setting, if the potential offender decides whether to commit crime at stage 1 (and 3), and punishment occurs in stage 2 (and 4 ), it follows that a lapse, as described in this article, corresponds to the extreme case where $\beta=0$, because when $\beta=0$, the person commits the crime regardless of the magnitude of the negative utility of potential punishment. Therefore, the model presented in this article is equivalent to one where $\beta$ is a random variable which takes on the values 0 or 1 respectively with probabilities $q$ and $1-q$. Although this paper does not investigate the more realistic case where individuals can draw intermediate values of $\beta$ 's in each period, it provides a good proxy for capturing the behavior of ordinary individuals who generally have $\beta$ 's close to 1 , but rarely draw $\beta$ 's close to 0 . It thereby points out that potential fluctuations in self-control can cause people to refrain from committing profitable crimes in stage 1 when they have high $\beta$ 's to avoid receiving the large sanction for repeat offenders when they draw low $\beta$ 's in the future.

Another assumption in this paper is that offenders have accurate expectations regarding the likelihood with which they will experience self-control problems. This is a variant of the assumption that offenders are sophisticated, i.e. "fully aware of her future self-control problems". (O'Donoghue and Rabin (2001) at p. 122) This assumption can be replaced by one of partial naivite, ${ }^{23}$ where individuals have mistaken beliefs about how much they are likely to suffer from present bias in the future. The temporal spillover effect of escalating penalty schemes continues to exist even in this setting. This is because even partially naive individuals know that if they enter stage 3 with a prior record, and experience self-control issues, they will be inclined to commit crime, because $b>\widehat{\beta} s_{2}=\widehat{\beta} b$ in scheme $E{ }^{24}$ where $\widehat{\beta}<1$ denotes the ex-convict's partially naive belief about his degree of self-control. ${ }^{25}$ Hence, when potential offenders do not experience self-control issues in stage 1, they can stop their future selves from being punished as repeat offenders by refraining from committing crime. On the other hand, if they experience self-control issues in stage 1, they will be inclined to commit crime, because they perceive a cost of $(1-\beta) b$ to delaying crime, which off-sets the cost of being punished as a repeat offender in stage $3 .^{26}$ Accordingly, under escalating punishment schemes the behavior of partially naive individuals with fluctuating self-control issues is identical to the behavior of the individuals analyzed in section 2.2., and the main effect identified in this article, namely the temporal spillover effect, is preserved.

\footnotetext{
${ }^{22}$ O'Donoghue and Rabin (2001) and Baumann and Friehe (2012) use similar utility functions.

23 See O'Donoghue and Rabin (2001) developing a model of partial naivite.

${ }^{24}$ See section 2.2 ., above.

${ }^{25} \mathrm{I}$ am following the notation and assumptions in O'Donoghue and Rabin (2001).

${ }^{26}$ This cost is negligible since $s_{2}=b$. Throughout the model it is assumed that an indifferent individual is deterred from committing crime, see supra note 17 . If he is not, then the results described here can be obtained by setting $s_{2}$ slightly above $b$.
} 


\subsection{What Happens if There are Potential Offenders with Criminal Benefits Exceeding Harm?}

In section 2, I assume that all individuals receive the same benefit from crime, and that such benefits are exceeded by the harm caused by crime. In this sub-section, I add into the model potential offenders who receive criminal benefits exceeding the harm from crime and show that escalating punishments are optimal under an even broader set of conditions. Then, I show that analogous results are obtained when there is a continuum of offender types and the density of criminal benefits among individuals is described by a continuous function. I only compare uniform and escalating sanction schemes.

\subsubsection{Two Types of Potential Offenders}

Let $b_{h}$ and $b_{l}$ be the criminal benefits of type $H$ and type $L$ individuals respectively, with $b_{h}>h>b_{l}$, and let the ratio of type $H$ individuals to type $L$ individuals be $\lambda$. Due to reasons underlying Observation 1, uniform schemes where $s \notin\left\{0, b_{l}, b_{h}\right\}$ are inefficient. Let $U_{0}, U_{b_{l}}$, and $U_{b_{h}}$ denote the remaining three uniform sanction schemes where subscripts denote the size of the uniform sanction. In addition to these three schemes, consider the escalating sanction schemes $E_{b_{l}}$ and $E_{b_{h}}$ where subscripts denote the size of $s_{2}$, and $s_{1}=0$ under both sanction schemes. Repeating the steps outlined in section 2 and making the relevant modifications, it can be verified that net social costs under each regime are given by:

$$
\begin{aligned}
C_{U_{0}} & =2\left(h-b_{l}\right)+2 \lambda\left(h-b_{h}\right) \\
C_{U_{b_{l}}} & =2 q\left(h-b_{l}\right)+2 \lambda\left(h-b_{h}\right)+2(q+\lambda) \theta b_{l} \\
C_{U_{b_{h}}} & =2 q\left(h-b_{l}\right)+2 \lambda q\left(h-b_{h}\right)+2 q(1+\lambda) \theta b_{h} \\
C_{E_{b_{l}}} & =\left(1+q^{2}\right)\left(h-b_{l}\right)+2 \lambda\left(h-b_{h}\right)+\left(\lambda+q^{2}\right) \theta b_{l} ; \text { and } \\
C_{E_{b_{h}}} & =\left(1+q^{2}\right)\left(h-b_{l}\right)+\lambda\left(1+q^{2}\right)\left(h-b_{h}\right)+(1+\lambda) q^{2} \theta b_{h}
\end{aligned}
$$

Next, one can determine the conditions under which $U_{0}$ is dominated by one of the two escalating punishment schemes. In particular, by separately comparing $C_{E_{b_{l}}}$ and $C_{E_{b_{h}}}$ with $C_{U_{0}}$, one can verify that one of the two escalating punishment schemes dominates $U_{0}$ if

$$
\max \left\{\frac{h-b_{l}-\lambda \theta b_{l}}{h-b_{l}+\theta b_{l}}, \frac{(1+\lambda)\left(h-b_{l}\right)-\lambda\left(b_{h}-b_{l}\right)}{(1+\lambda)\left(h+\theta b_{h}-b_{l}\right)-\lambda\left(b_{h}-b_{l}\right)}\right\}>q^{2}
$$

In the remainder of the analysis, I will assume that (14) holds, because if it does not, no deterrence is optimal and the case is relatively uninteresting. ${ }^{27}$

By comparing (10) and (11) one can note that $U_{b_{h}}$ is likely to be dominated by $U_{b_{l}}$ if $b_{h}$ is sufficiently greater than $h$. This follows because $U_{b_{h}}$ deters the

\footnotetext{
${ }^{27}$ This follows because when (14) does not hold $U_{i}$ is dominated by $E_{i}$ for $i \in\left\{b_{l}, b_{h}\right\}$. This can be verified by noting that a violation of (14) implies (i) that $\frac{\theta b_{l}}{h-b_{l}} \geq \frac{1+\lambda}{q^{2}+\lambda}-1>$ $\frac{1+\lambda}{q(2-q)+\lambda}-1$, which is the condition for $E_{b_{l}}$ dominating $U_{b_{l}}$ and (ii) that $\frac{\theta b_{h}}{h-b_{l}-\frac{\lambda}{1+\lambda}\left(b_{h}-b_{l}\right)} \geq$ $\frac{1}{q^{2}}-1>\frac{1}{q(2-q)}-1$, which is the condition for $E_{b_{h}}$ dominating $U_{b_{h}}$.
} 
commission of efficient crimes (since $b_{h}>h$ ). On the other hand, the only benefit is a reduction in punishment costs, which is borne by fewer type $H$ individuals committing crime and being punished. More specifically, $U_{b_{h}}$ is dominated by $U_{b_{l}}$ if

$$
b_{h}-h>\theta b_{l}-\frac{(1+\lambda) q \theta}{\lambda(1-q)}\left(b_{h}-b_{l}\right)
$$

If (15) holds, one can compare $C_{E_{b_{l}}}$ to $C_{U_{b_{l}}}$ to obtain a sufficient condition for the optimality of escalating punishment schemes:

$$
\frac{\theta b_{l}}{h-b_{l}}>\frac{1+\lambda}{q(2-q)+\lambda}-1
$$

Note that this condition is weaker than the corresponding condition in (8), because the right hand side of (16) is decreasing in $\lambda$ and achieves its maximum when $\lambda=0$. Therefore, the inclusion of type $H$ individuals whose benefits sufficiently exceed $h$ makes it more likely for escalating penalty schemes to be optimal. A similar conclusion is reached when $b_{h}$ is close to $h$ and (15) does not hold. In this case, one can compare $C_{E_{b_{h}}}$ to $C_{U_{b_{h}}}$ to derive a condition under which escalating penalties are optimal, which is given by:

$$
\frac{\theta b_{h}}{h-b_{l}-\frac{\lambda}{1+\lambda}\left(b_{h}-b_{l}\right)}>\frac{1}{q(2-q)}-1
$$

This, too, is a condition weaker than the corresponding condition in (8), because the left hand side of (17) is increasing in $\lambda$, and achieves its minimum when $\lambda=0$. Accordingly, the inclusion of type $H$ individuals weakens the conditions under which escalating penalties are optimal, regardless of by how much $b_{h}$ exceeds $h$.

The rationale behind this result is simple. Type $H$ individuals are people who contribute to total social welfare when they commit crime, but whose punishment is equally costly as the punishment of type $L$ individuals. Therefore, their inclusion increases the relative cost of punishment in comparison to gains from deterrence. Since the main feature of escalating punishments is to reduce punishment costs at the price of a reduction in deterrence, they are more likely to be optimal when this price is relatively low.

\subsubsection{Continuum of Types of Potential Offenders}

To extend the analysis to the case where there is a continuum of potential offender types, let $z(b)$ describe the density of benefits among individuals, and let it be positive for all $b \geq 0$. If $Z($.$) is the corresponding cumulative distribu-$ tion function, one can verify that the measure of crimes committed under any uniform sanction scheme is given by:

$$
2 q Z(s)+2(1-Z(s))
$$

where $s$ denotes the uniform sanction. This follows, because individuals with $b \leq s$ refrain from committing crime whenever they possess self-control, and the 
rest of the individuals always commit crime. As such, net social costs are given by:

$$
C_{U_{s}}=2(q Z(s)+(1-Z(s))) \theta s+2 q \int_{0}^{s}(h-b) z(b) d b+2 \int_{s}^{\infty}(h-b) z(b) d b
$$

Next, consider the corresponding escalating penalty scheme which imposes a sanction of $s$ to repeat offenders and 0 to first time offenders. Faced with this sanction scheme -due to reasons explained in sub-section 2.2.- individuals with $b \leq s$ who possess self-control in the first period refrain from committing crime in the first period and commit crime in the second period. Those who lapse in the first period commit crime in the second period only if they re-lapse. Individuals with $b>s$ commit crime in both periods. Therefore, net social costs are given by:

$$
C_{E_{s}}=\left(q^{2} Z(s)+(1-Z(s))\right) \theta s+\left(1+q^{2}\right) \int_{0}^{s}(h-b) z(b) d b+2 \int_{s}^{\infty}(h-b) z(b) d b
$$

Comparing (19) and (20) reveals that $E_{s}$ leads to greater social welfare than $U_{s}$ when

$$
\frac{\theta s}{\int_{0}^{s}(h-b) z(b) d b}>\frac{1-q(2-q)}{q(2-q) Z(s)+1-Z(s)}
$$

(21) is the condition that corresponds to (16) and (17) when there is a continuum of types. It should be noted that this is a sufficient -and not necessary- condition. In this setting, there could be many escalating punishments with $s_{1} \neq 0$ that out perform $E_{s}$. But, since the purpose here is to demonstrate that escalating penalties, in general, can out perform uniform sanction schemes, focusing on (21) should be harmless. It is easy to see that for any $s>0$, there is a $\theta$ large enough such that (21) holds. As such, as indicated by the discussion in section 2 and sub-section 3.2.1., escalating punishments are optimal as long as punishment is sufficiently costly and a degree of deterrence is socially desirable.

One can also conjecture about how the distribution of criminal benefits affects the analysis. The greater the densities $z($.$) distributes over large b$ 's, the more likely are escalating penalties optimal. One can arrive at this conclusion, which is consistent with results discussed in sub-section 3.2.1., by noting that $Z(s)$ is smaller when $z($.$) distributes greater values to large b$ 's. Therefore, the right hand side of (21) is smaller. Furthermore, there is a second effect; when $z($.$) assigns higher densities to large b$ 's, the integrand in the denominator of the left hand side of (21) is smaller in magnitude for small values of $b$, which are precisely the $b$ 's that are being summed by the integral. Therefore the left hand side of (21) is greater. Accordingly, escalating penalties are more likely to be optimal when $z($.$) assigns greater densities to large criminal benefits.$

Overall, sub-sections 3.2.1. and 3.2.2. suggest that results presented in section 2 extend to more sophisticated models where there are multiple or an 
infinite number of potential offender types, and that escalating penalties are more likely to be optimal when the average benefit from crime is high. Next, I consider whether results change if, as suggested by some scholars, criminal benefits do not enter the social welfare function.

\subsection{Excluding Criminal Benefits from Social Welfare}

The analysis in section 3 was conducted by conventionally including criminal benefits in the social welfare function. However, there is a controversial and unsettled debate as to whether this is the proper way to proceed. Fortunately, the nature of the results presented in this article is not altered by the particular assumption concerning the inclusion (or exclusion) of criminal benefits in social welfare.

First, note that potential offenders' behavior does not depend at all on whether or not criminal benefits enter the social welfare function. Therefore, the portion of the analysis that relates to individuals' best responses to sanctions chosen by the government remains unchanged. Furthermore, observations 1, 2, and 3 also remain unaffected, because these rely only on the size and frequency of punishment costs to identify inefficient sanction schemes. The remaining parts of the analysis can quickly be repeated by excluding criminal benefits from social welfare. This corresponds to removing $b$ from the denominator of (8), which yields: ${ }^{28}$

$$
\frac{1}{2 q-q^{2}}-1<\frac{\theta b}{h}<\frac{1}{q^{2}}-1
$$

(22) establishes that the nature of the results are preserved when criminal benefits are excluded from the social welfare function. Quantitatively, given that $q$ is small, the constraint that is likely to be more problematic is the one that requires the ratio between the per person punishment cost and the cost of crime to be great. Because this ratio is greater when criminal benefits are included -it increases from $\frac{\theta b}{h}$ to $\frac{\theta b}{h-b}-$, escalating penalties are more likely to be optimal when criminal benefits count. This result is consistent with the previous discussion in sub-section 3.2., which suggests that escalating penalties are more likely to be optimal when the average criminal benefit is large.

\subsection{Is the Analysis Equally Applicable when Individuals can be Wrongfully Convicted?}

At first glance, it appears as if models incorporating weak-willed individuals should produce the same results as models incorporating the possibility of wrongful convictions. However, there are many important differences between the two models, which become apparent once one carefully reviews them. First, unlike wrongfully convicted individuals, offenders who lapse generate actual harms by committing crime. Second, although the number of individuals who lapse is constant (i.e. $q$ fraction of the population in both periods) the number of individuals who are wrongfully convicted depends on individuals'

\footnotetext{
${ }^{28}$ This can quickly be verified by modifying (P.1.)-(P.9.) to reflect the exclusion of criminal benefits from welfare and re-obtaining the two conditions which generate (8) in corollary 1.
} 
decisions to commit crime. Third, whereas a wrongful conviction occurs only after an individual decides whether to commit a crime, a lapse, by definition, occurs to determine if one has the ability to decide whether to commit crime. Fourth, there are unsettled debates as to what the proper method is to include wrongful convictions in law enforcement models. ${ }^{29}$ Due to these reasons, further investigation is required before one can conclude that the instant model can (or cannot) be used to evaluate the desirability of escalating punishment schemes when wrongful convictions are possible.

\subsection{Concluding Remarks}

This article represents an attempt to incorporate weak-willed potential offenders into the standard law enforcement model to investigate the social desirability of repeat offender laws. When potential offenders are weak-willed and punishment is costly, a rationale emerges for punishing repeat offenders more severely, which is based on offenders' precautionary abstention from crime. Optimality of escalating punishment requires that punishment costs are significant, and that some degree of deterrence is desirable. Once these conditions are met, escalating punishments become optimal in a variety of settings; they are socially desirable when all or only some crimes are inefficient, when potential offenders' benefits count, and when they are excluded from social welfare. Furthermore, the optimality of escalating penalties does not require punishment to cost more when committed by individuals who lapse. Accordingly the instant article provides a behavioral justification for escalating punishment schemes, which is valid under a wide variety of assumptions.

\section{References}

[1] Baumann, F. and T. Friehe. "Self-report to self-control? A note", The Journal of Socio-Economics, 41, (2012): 727-729.

[2] Chu, C. Y. C., S. Hu and T. Huang. "Punishing Repeat Offenders More Severely", International Review of Law and Economics, 20, (2000): 127140.

[3] Cooter, R. "Lapses, Conflict, and Akrasia in Torts and Crimes: Towards an Economic Theory of the Will", International Review of Law and Economics, 11, (1991): 149-164.

[4] Emons, W. "Escalating Penalties for Repeat Offenders", International Review of Law and Economics, 27, (2007): 170-178.

[5] Fennell, L. "Willpower and Legal Policy", Annual Review of Law and Social Science, 5, (2009): 91-113.

\footnotetext{
${ }^{29}$ In particular, the standard approach -as exemplified by Png (1986), Chu et al. (2000), Mungan (2011) and Rizzolli and Saraceno (In Press)- is to assume that wrongful convictions lower deterrence. However, there is a debate, as reflected in Garoupa and Rizzolli (Forthcoming) and Lando (2006), as to whether, and when, wrongful convictions lower deterrence.
} 
[6] Friehe, T. "Escalating penalties for repeat offenders: a note on the role of information", Journal of Economics, 97, (2009): 165-183.

[7] Funk, P. "On the Effective Use of Stigma as a Crime-deterrent", European Economic Review, 48, (2004): 715-728.

[8] Garoupa, N. and M. Rizzolli. "Wrongful Convictions Do Lower Deterrence", Journal of Institutional and Theoretical Economics, 168, (2012): Forthcoming.

[9] Jolls, C., Sunstein, C., Thaler, R., "A Behavioral Approach to Law and Economics", Stanford Law Review, 50, (1998): 1471-1550.

[10] Korobkin, R., and T. Ulen, "Law and Behavioral Science: Removing the Rationality Assumption from Law and Economics", California Law Review, 88, (2000): 1051-1144.

[11] Lando, H. "Does Wrongful Conviction Lower Deterrence?" Journal of Legal Studies, 35, (2006): 327-337.

[12] McAdams, R. "Present Bias and Criminal Law" University of Illinois Law Review, 2011, (2011): 1607-31.

[13] McAdams, R. and T. Ulen, "Behavioral Criminal Law and Economics", in Criminal Law and Economics (Nuno Garoupa ed. 2009)

[14] McCannon, B. "Differentiating Between First and Repeat Offenders", Contemporary Economic Policy, 27, (2009): 76-85.

[15] Miceli, T. "Escalating Interest in Escalating Penalties", University of Connecticut, Working Paper 2012-08.

[16] Miceli, T. J. and C. Bucci. "A Simple Theory of Increasing Penalties for Repeat Offenders", Review of Law and Economics, 1, (2005): 71-80.

[17] Mungan, M. C. "Repeat Offenders: If They Learn, We Punish Them More Severely" International Review of Law and Economics, 30, (2010): 173-177.

[18] Mungan, M. C. "A Utilitarian Justification for Heightened Standards of Proof in Criminal Trials" Journal of Institutional and Theoretical Economics 167, (2011): 352-370.

[19] Mungan, M. C. "The Law and Economics of Fluctuating Criminal Tendencies and Incapacitation" Maryland Law Review 72, (2012):

[20] Mungan, M. C. "Optimal Warning Strategies: Punishment Ought not to be Inflicted where the Penal Provision is not Properly Conveyed" Review of Law and Economics , (Forthcoming):

[21] O'Donoghue, T., M. Rabin. "Choice and procrastination", Quarterly Journal of Economics 116, (2001): 121-160. 
[22] Png, I., "Optimal Subsidies and Damages in the Presence of Judicial Error", International Review of Law and Economics, 6, (1986): 101-105.

[23] Polinsky, A. M. and S. Shavell. "On offense history and the theory of deterrence", International Review of Law and Economics, 18, (1998): 305-324.

[24] Polinsky, A. M. and S. Shavell. "Public Enforcement of Law", in Handbook of Law and Economics 403-454 (A. Mitchell Polinsky \& Steven Shavell, eds. 2007)

[25] Polinsky, M., and D. Rubinfeld, "A model of fines for repeat offenders", Journal of Public Economics, 46, (1991): 291-306.

[26] Rasmusen, E. B. "Stigma and Self-Fulfilling Expectations of Criminality", Journal of Law and Economics, 39, (1996): 519-544.

[27] Rizzolli, M. and M. Saraceno. "Better That Ten Guilty Persons Escape: Punishment Costs Explain the Standard of Evidence" Public Choice, (In Press), available at http://dx.doi.org/10.1007/s11127-011-9867-y.

[28] Robinson, P. H. and J. M. Darley, "Does Criminal Law Deter? A Behavioral Science Investigation" Oxford Journal of Legal Studies, 24, (2004): 173 205.

[29] Stigler, G. J. "The Optimum Enforcement of Laws." Journal of Political Economy, 78, (1970): 526-536.

[30] Utset, M. "Hyperbolic Criminals and Repeated Time-Inconsistent Misconduct", Houston Law Review, 44, (2007): 609-677. 